Proceedings

\title{
Optimization of Process Parameters on Microstructure and Mechanical Properties of ADC 12 Alloy Aptomat Contact Fab- ricated by Thixoextrusion
}

\author{
Giang Lai Dang ${ }^{1}$, Tuan Nguyen Anh ${ }^{1, *}$, Van Luu Dao ${ }^{1}$, Du Nguyen Vinh ${ }^{2}$ and Tien Nguyen Manh ${ }^{1}$ \\ 1 Le Quy Don Technical University, Faculty of Mechanical Engineering \\ Hanoi, Vietnam \\ 2 Department of Sciece and Technology Hochiminh City \\ Ho Chi Minh, Vietnam \\ * Correspondence: tuantamhop@gmail.com \\ † Viet Nam, January 7, 2021.
}

Citation: Dang, G.L.; Anh, T.N.; Dao, V.L.; Vinh, D.N.; Manh, T.N.

Optimization of Process Parameters on Microstructure and Mechanical Properties of ADC 12 Alloy Aptomat Contact Fabricated by Thixoextru-

sion. 2021, 3,

https://doi.org/10.3390/xxxxx

Published: 22 February 2021

Publisher's Note: MDPI stays neutral with regard to jurisdictional claims in published maps and institutional affiliations.

Copyright: $\odot 2021$ by the authors. Submitted for possible open access publication under the terms and conditions of the Creative Commons Attribution (CC BY) license (http://creativecommons.org/licenses /by/4.0/).

\begin{abstract}
The mechanical properties of thixoextrusion components can be improved by controllable processing parameters such as the solid fraction of alloy, holding time, punch velocity, heat treatment and die temperature. In this study, the effects of thixoforming parameters on the microstructures and mechanical properties of thixoextrusion ADC12 alloy Aptomat Contact are studied. ADC 12 has excellent castability with high fluidity and low shrinkage rate, so it is widely used in industry, especially in automotive and motorcycle engine part casting. It is a near eutectic alloy with high strength and low ductility $(1 \%)$. The optimization parameters mechanical properties were investigated by changing the punch velocity, specimen temperature and holding time. The results also indicated optimal value at punch velocity $(15 \mathrm{~mm} / \mathrm{s})$, specimen temperature $\left(560^{\circ} \mathrm{C}\right)$ and holding time (5 minutes) which was changed microstructure from eutectic dendrite to globular grain increasing the ductility $(3.3 \%)$ of this alloy during the semi-solid forming process while remaining mechanical properties leads to an increase in the quality of finished parts.
\end{abstract}

Keywords: Thixoextrusion; Thixoforming; Cooling slope; ADC12 Alloy.

\section{Introduction}

Semi-solid metal (SSM) processing originated from work by researchers at MIT in 1971 experimenting on the rheological behaviour of Sn-15Pb alloy [1]. The semisolid slurry with a spheroidal microstructure of 0.4-0.6 weight fraction solid had a very low value of flow resistance and that it would be possible to use this in developing new forming processes. SSM process combines advantages of casting (Liquid) and forming (solid) processes [2]. It allows the fabrication of parts with complex shapes such as the casting method and the mechanical properties close to that of forging.

The key point of SSM is the thixotropy of metallic alloys at the semi-solid state which can appear between liquidus and solidus temperatures of the alloy and the microstructure of the semi-solid alloy is non-dendritic consisting of spheroidal solid-phase suspended in the liquid phase during forming.

The SSM has been widely applied in industry with aluminum alloys [3]. The NADCA Standard (2006) lists aluminum alloys recommended for use in this method with aluminum alloys containing 5.0 to $17.0 \mathrm{wt}$. \% Si. However, popular cast alloys such as A383, A384, ADC 12 (Japan) and A 125 (Russia) are not included in this list. According to experts, aluminum alloys with $11-13 \mathrm{wt}$. \% Si content cannot form the required structure in the process of thixoforming, therefore, they are not recommended for use [4]. 
ADC 12 has excellent cast ability with high fluidity and low shrinkage rate, so it is widely used in industry, especially in automotive and motorcycle piston casting. ADC 12 (Si 12\%wt) is an eutectic alloy with eutectic dendrite microstructure has high strength, high thermal stability and low ductility (about 1\%) [5, 6]. Few investigators have attempted to modify the cast structure of ADC 12 alloy using Near-Liquidus Squeeze Casting (NLSC) [7], Strain-Induced metal activation (SIMA) [8] and Yb, samarium addition $[9,10]$. In this study, the cooling slope method is used to change the eutectic dendrite to equiaxed dendrites microstructure with small particle size to change to turn into a globular microstructure when re-heating the semi-solid temperature for thixoforming. ADC 12 with globular microstructure increase the ductility of this alloy during the semi-solid forming process while remaining mechanical properties leads to an increase in the quality of finished parts such as the piston, Aptomat Contact, increasing the reliability of the finishing part.

In this paper, the semi-solid die has been fabricated to serve the optimization of parameters of press temperature, holding time and velocity of the punch to the strength and elongation of Aptomat Contact, thereby studying the effects of these processing parameters on the thixoextrusion.

\section{Material and Method}

\subsection{Material}

Chemical compositions of Aluminum ADC 12 alloy are determined by Spectrolab machine in Laboratory of Institute of Technology which present in table 1. It is worth not-ing that the silicon content is $11.6 \%$ (eutectic alloy) and $\mathrm{Cu} 2 \%$ wt this metal was added to increase the strength and machinable.it also reduces the slope of the cooling curve and creates a semi-solid temperature range for the eutectic alloys [11].

The DSC (Differential Scanning Calorimetry) method has been used to accurately determine the semi-solid window temperature range for this alloy, This is the method commonly used to determine the material transition temperature that show in Fig 1. Cube $2 \mathrm{~mm}^{3}$ reheated to $700^{\circ} \mathrm{C}$ with cooling rate $10^{\circ} \mathrm{C} / \mathrm{min}$ and then cooling with the same velocity in DSC 2500 at physic department in Le Quy Don University. The result shows that the melting and solidus temperature of ADC 12 are $574{ }^{\circ} \mathrm{C}$ and $500^{\circ} \mathrm{C}$ respectively (fig 1a). Based on the cooling curve to determine the suitable semi-solid machining temperature for $\mathrm{ADC} 12$ is $560-566^{\circ} \mathrm{C}$ (fig 1b). Machining temperature is a very important value that directly affects the liquid phase fraction of the billet in the forming process, which determines the integrity of the part.

Table 1. Chemical composition of ADC12 alloy

\begin{tabular}{llllllllllll}
\hline Element & $\mathrm{Si}$ & $\mathrm{Fe}$ & $\mathrm{Cu}$ & $\mathrm{Mn}$ & $\mathrm{Mg}$ & $\mathrm{Cr}$ & $\mathrm{Ni}$ & $\mathrm{Zn}$ & $\mathrm{Ti}$ & $\mathrm{Pb}$ & $\mathrm{Al}$ \\
\hline $\mathrm{wt} \%$ & 11.58 & 0.63 & 2.09 & 0.17 & 0.081 & 0.023 & 0.055 & 0.77 & 0.048 & 0.056 & 84.5 \\
\hline
\end{tabular}

\subsection{Preparation of billet}

To create billet for the semi-solid forming process, the research has built a schemes of cooling slope casting Fig 2a. The billets creation process for the cooling slope are conducted as follows, 1100 gram aluminum alloy was put in a graphite crucible and melted by an Nabertherm electric resistance furnace at $700^{\circ} \mathrm{C}$ and then cooling to pouring temperature. The melting alloy poured onto the surface of cooling slope plate made of stainless steel with a water-circulating cooling system, semi-solid slurry out of the cooling slope collected into stainless steel mold. The mold is placed in furnance to keep the temperature at $300^{\circ} \mathrm{C}$ within 5 minutes then quenched in water. Type $\mathrm{K}$ thermocouple 
were placed at different location of cooling slope to measure the temperature. The billet obtained from the casting process is shown in Fig $2 \mathrm{~b}$.

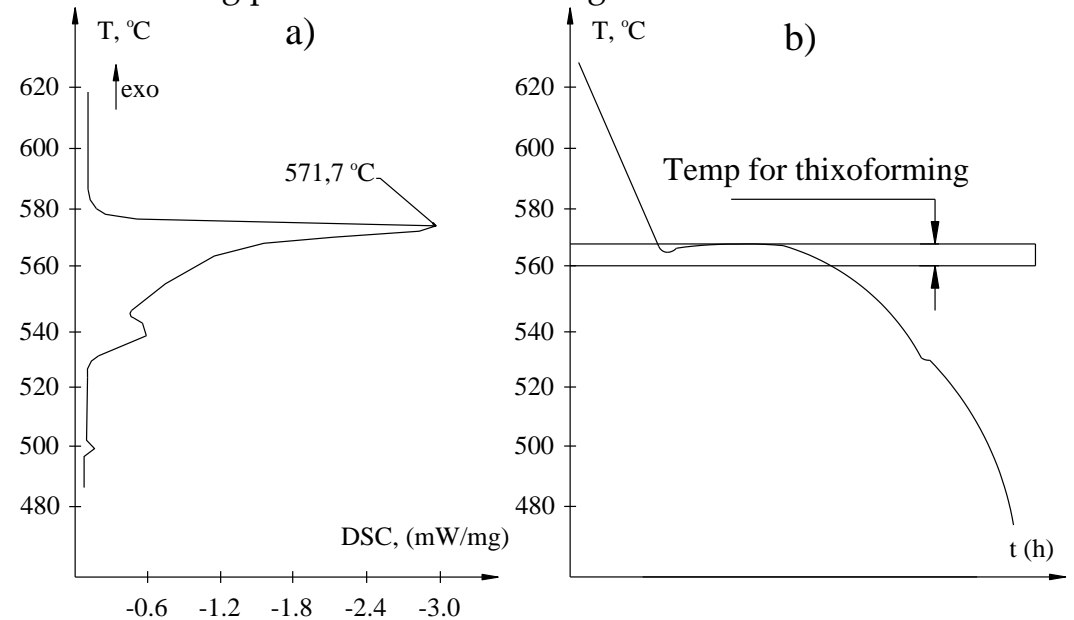

Figure 1. DSC curve of ADC 12 aluminum alloy

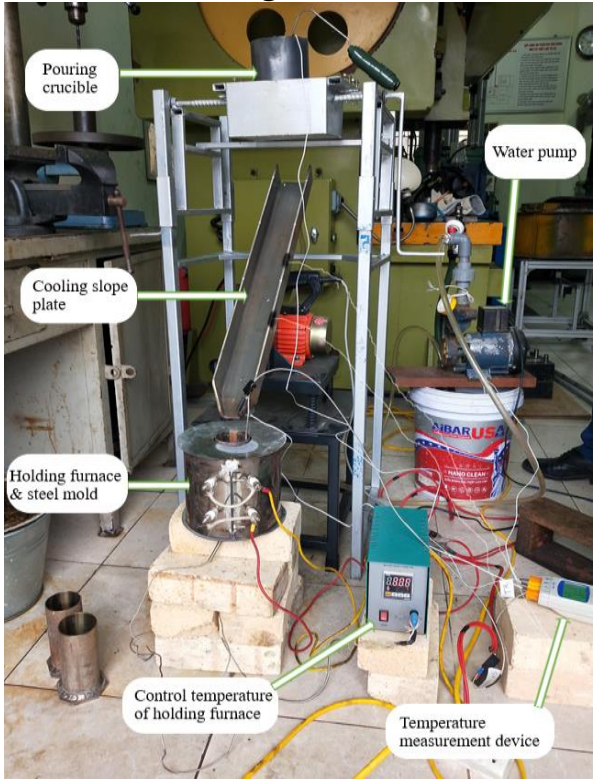

(a)

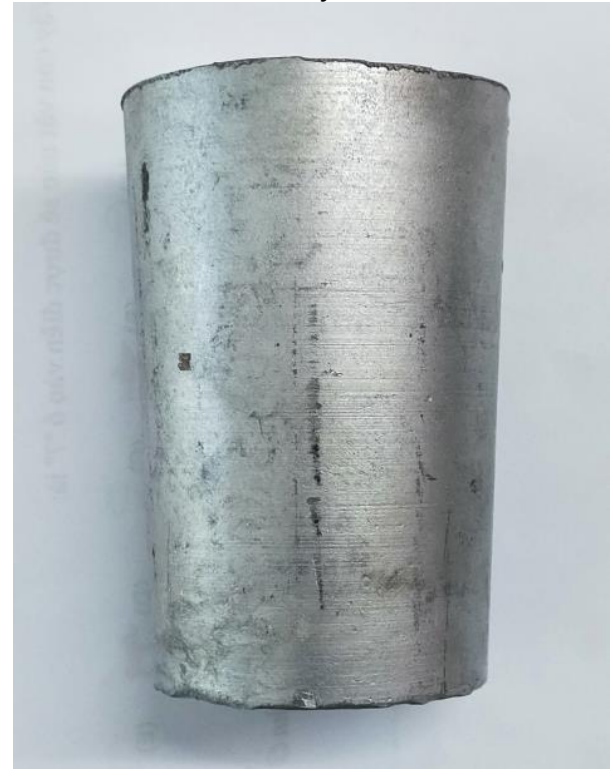

(b)

Figure 2. Schemes of cooling slope casting: (a) Shematic diagram of cooling slope casting; (b) Billet after casting.

\subsection{Organization of experiment and sample analysis}

The casting billet is cut into pieces with dimensions $\Phi 50 \times 20$ (Fig 3b) then heated by resistance furnace to a specified temperature, to accurately control the temperature of billet, type k thermocouple was inserted in the centre of the billet in Fig 3a, as the billet achieve a semi-solid state that is pressed into the mold cavity to form the desired part (Fig 3b) by 100 tons hydraulic press.

Factors investigated during the process consisted of three input parameters, the workpiece temperature selected at 560 and $566^{\circ} \mathrm{C}$ and denoted by $\mathrm{x} 1$, the holding time selected 5 and 15 minutes denoted $\times 2$ and punch velocity selected 3 and $15 \mathrm{~mm} / \mathrm{s}$ denoted by $x 3$. Their values are shown in Table 2 . Two responses values of the study, ultimate tensile strength and elongation, were determined by cutting and tensile testing on MST Landmark as shown in Fig 4. To improve the accuracy of the obtained regression function, the study conducted central experiments with three repeating experiments denoted as numbered 0 in the result table 4 . 


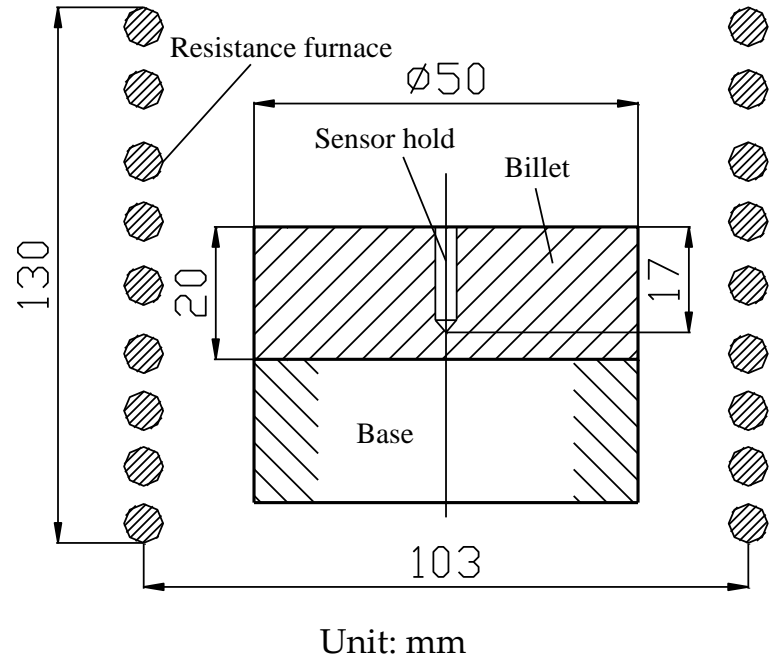

(a)
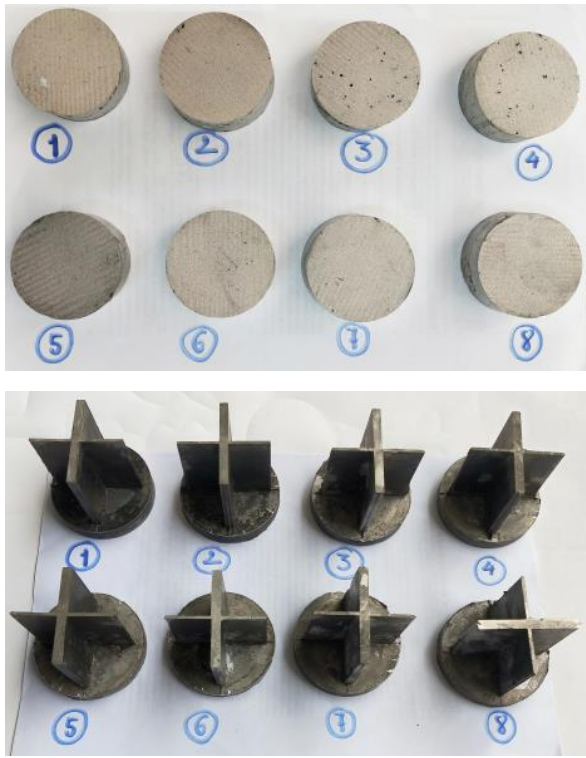

(b)

Figure 3. The experiment model, billets and products (a) The experiment model;

(b) Billets befor forming and products

Table 2. Factors and level of the input value in the experiment

\begin{tabular}{ccccc}
\hline \multirow{2}{*}{ Symbol } & \multirow{2}{*}{ Factor } & Unit & \multicolumn{2}{c}{ Processing parameter } \\
\cline { 4 - 5 } & & & -1 & 1 \\
\hline $\mathbf{x}_{1}$ & Specimen temperature & ${ }^{\circ} \mathrm{C}$ & 560 & 566 \\
$\mathbf{x}_{2}$ & Holding time & $\mathrm{min}$ & 5 & 15 \\
$\mathbf{x}_{3}$ & Punch velocity & $\mathrm{mm} / \mathrm{s}$ & 3 & 15 \\
\hline
\end{tabular}

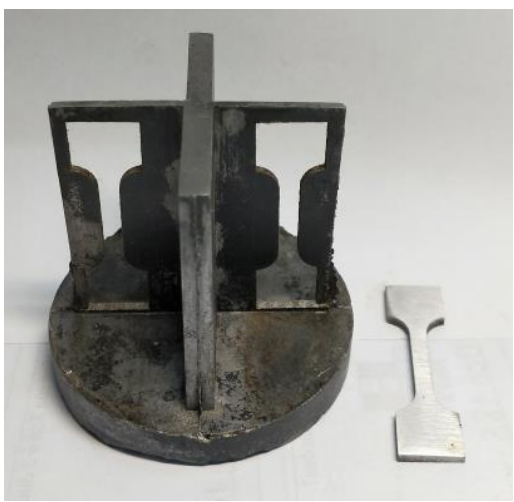

(a)

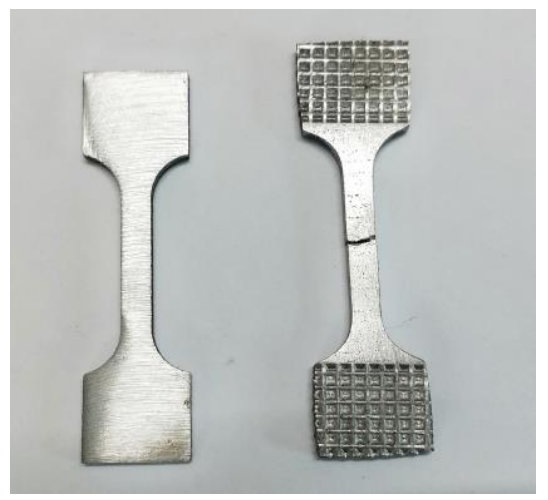

(b)

Figure 4. Schemes of cooling slope casting: (a) Shematic diagram of cooling slope casting; (b) Billet after casting.

\section{Result and discussion}

\subsection{Comparison of the microstructure between cooling slope casting and thixoextrusion}

Figure 5a shows the microstructure of ADC12 alloy that was cast at a pouring temperature of $580{ }^{\circ} \mathrm{C}$ by without cooling slope. The slope length, slope angle and slope temperature used were $300 \mathrm{~mm}, 65^{\circ}$ and room temperature, respectively. The bright phase is primary a-Al phase, and the grey phase surrounding the bight phases is Si eutectic phase. It was observed that a large number of fine primary globular a-Al grain 
formed by the cooling slope casting and uniform cooling parallel to dendrites fragmentation and spheroidization during casting process (fig $5 \mathrm{a}$ ). It can be explained as follows, Grains nucleated on plate of slope along with the detached nuclei grow during movement from the top to the bottom of the cooling slope [3]. Most of the nucleation that has occurred at the top of the cooling slope may be considered as a general source of nuclei.

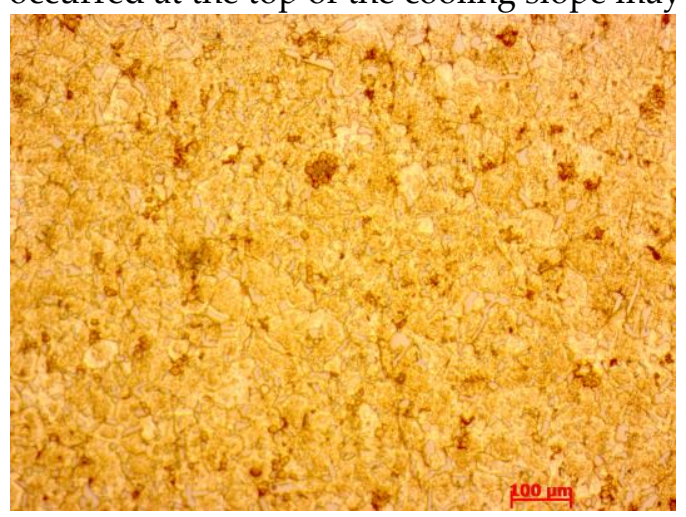

(a)

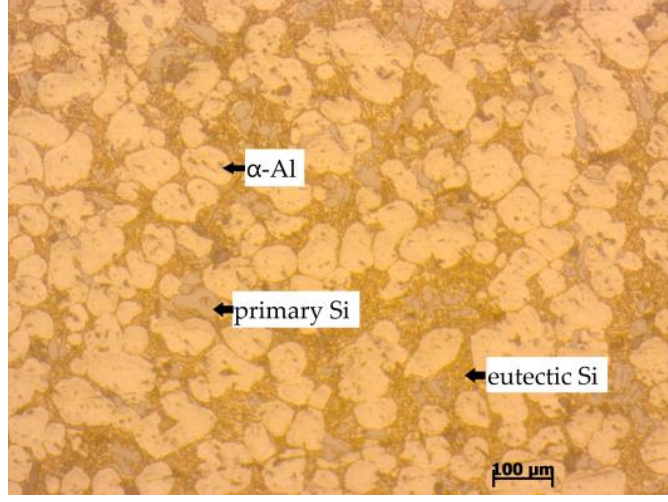

(b)

Figure 5. Comparison of the microstructure of cooling slope casting and thixoextrusion: (a) Microstructure of cooling slope casting; (b) Microstructure of thixoextrusion.

As shown in Figure 5b, the microstructure obtained after thixoextrusion has a globular microstructure of primary $\alpha-\mathrm{Al}$, the research has created a uniform globular microstructure in the finished parts. This is one of the reasons to improve the strength and elongation of this parts [12]. This phenomenon can be explained as after heating the billet to a semi-solid state, the diffusion process takes place strongly at high temperatures, combined with the Ostwald ripening phenomenon to help globular the aluminum grains.

\subsection{Comparison of mechaniacal properties between die casting and thixoextrusion}

Table 3 presents the results of measuring the properties of a thixoextrusion "Aptomat Contact" from ADC12 alloy. Reference data were taken from the publication. The appearance of thixoformed products and the scheme for cutting out the test specimens are shown in Fig. 4, the microstructure of the part is shown in Fig. 5b. The results showed that there is a significant increase in the strength and elongation of the parts formed by semi-solid processing method.

Table 3. Mechanical properties of ADC12 alloy and equivalence

\begin{tabular}{clccc}
\hline \multirow{2}{*}{$\begin{array}{c}\text { Item } \\
\text { No. }\end{array}$} & \multicolumn{1}{c}{ Manufacturing technology, alloy } & \multicolumn{3}{c}{ Mechanical properties } \\
\cline { 3 - 5 } & \multicolumn{1}{c}{ ADC12 and equivalence } & UTS, MPa & $0.2 \%$ YS, MPa & $\delta, \%$ \\
\hline $\mathbf{1}$ & Die casting [13] & 228 & 154 & 1.4 \\
$\mathbf{2}$ & A/25 Die casting [14] & 220 & 220 & 0.5 \\
3 & A/25 Liquid forming (P = 150 MPa) [14] & 250 & 240 & 0.85 \\
$\mathbf{4}$ & Thixoextrusion part & 283 & 251 & 2.5 \\
\hline
\end{tabular}

\subsection{Results of experiments}

Thixoextrusion is accepted by many manufacturing industries. In order to design experimental work, three processing parameters, namely specimen temperature, holding time and punch velocity, were chosen as input variables whereas ultimate tensile strength and elongation obtained from the tensile test were recorded as responses. A series of trial experiments were carried out to find the limit of input variables. Limits of variables were notified as $-1,0$ and +1 for the lower value, middle value and higher value and also input variables were notified as A for specimen temperature ( C), B for holding 
time (min) and $C$ for punch velocity $(\mathrm{mm} / \mathrm{s})$. There are 11 test trials performed based on the design on the experiment method as shown in Table 4.

Table 4. Experimental results

\begin{tabular}{ccccccc}
\hline & & Factor 1 & \multicolumn{2}{c}{ Factor 2 } & Factor 3 Response 1 Response 2 \\
Std & Run & $\begin{array}{c}\text { A:Specimen } \\
\text { temp }\end{array}$ & $\begin{array}{c}\text { B:Holding } \\
\text { time }\end{array}$ & velocity & UTS & Elongation \\
\cline { 4 - 7 } & & ${ }^{\circ}$ C & min & $\mathrm{mm} / \mathrm{s}$ & $\mathrm{MPa}$ & $\delta, \%$ \\
\hline 1 & 11 & -1 & -1 & -1 & 304 & 3 \\
2 & 5 & 1 & -1 & -1 & 248 & 2 \\
3 & 9 & -1 & 1 & -1 & 287 & 2.3 \\
4 & 4 & 1 & 1 & -1 & 277 & 2.5 \\
5 & 8 & -1 & -1 & 1 & 311 & 3.3 \\
6 & 6 & 1 & -1 & 1 & 254 & 1.6 \\
7 & 2 & -1 & 1 & 1 & 305 & 3.2 \\
8 & 3 & 1 & 1 & 1 & 285 & 2.3 \\
9 & 10 & 0 & 0 & 0 & 288 & 2.4 \\
10 & 1 & 0 & 0 & 0 & 287 & 2.3 \\
11 & 7 & 0 & 0 & 0 & 285 & 2.4 \\
\hline
\end{tabular}

\subsection{Optimization of ultimate tensile strength and elongation for the productions}

ANOVA analysis is used to determine the adequacy and significance of the model, in addition, to evaluate the effect of lack of fit on model and significance of individual model coefficient. Selecting stepwise backward disqualification method to superannuate the insignificant term from the model and result of ANOVA table for the ultimate tensile strength (UTS) and elongation are described in Tables 5 and 6, respectively. The values of $\mathrm{f}$ are 92.53 and 27.38 respectively for UTS and the elongation indicates the model is very significant. There is only a $0.01 \%$ chance that an F-value of this magnitude could occur due to noise. There is $0.07 \%$ value of $\mathrm{F}$ that is probable for interference for elongation and for UTS it is $0.01 \%$. In both models, the effect of the specimen temperature accounts for a significant value, in the UTS model, the effect of temperature is $65.6 \%$ and in the elongation model this value is $56.1 \%$. In the UTS model, the effects of the holding time and punch velocity are quite equilibrium less than $5 \%$, while in the elongation model these two variables do not appear. In these models, the value of the coefficient of determination $\mathrm{R}^{2}$ and Adjusted $\mathrm{R}^{2}$ are both greater than or equal to $90 \%$, which shows that the found models are statistically significant, $\left(R^{2}=0.98\right.$ means $98 \%$ of the total variability observed in this model, Adeq Precision measures the signal-to-noise ratio. This ratios greater than 4 indicates an adequate signal [15]).

The following equations are the final empirical models in terms of coded factors for UTS and the elongation:

$$
\begin{gathered}
\mathrm{UTS}=283.88-17.87 * \mathrm{~A}+4.63 * \mathrm{~B}+4.88^{*} \mathrm{C}+10.38^{*} \mathrm{AB} \\
\text { Elongation }=2.53-0.425^{*} \mathrm{~A}+0.25 * \mathrm{AB}-0.225^{*} \mathrm{AC}
\end{gathered}
$$


Table 5. ANOVA for ultimate tensile strength

\begin{tabular}{|c|c|c|c|c|c|c|}
\hline Source & $\begin{array}{l}\text { Sum of } \\
\text { Squares }\end{array}$ & df & $\begin{array}{c}\text { Mean } \\
\text { Square }\end{array}$ & F-value & p-value & $\%$ Contribution \\
\hline Model & 3778.50 & 4 & 944.63 & 92.53 & $<0.0001$ & significant \\
\hline A-Specimen temp & 2556.12 & 1 & 2556.12 & 250.40 & $<0.0001$ & $66.5 \%$ \\
\hline B-Holding time & 171.13 & 1 & 171.13 & 16.76 & 0.0094 & $4.4 \%$ \\
\hline C-Punch velocity & 190.13 & 1 & 190.13 & 18.62 & 0.0076 & $4.9 \%$ \\
\hline $\mathrm{AB}$ & 861.13 & 1 & 861.13 & 84.36 & 0.0003 & $22.4 \%$ \\
\hline Curvature & 17.00 & 1 & 17.00 & 1.67 & 0.2533 & \\
\hline Residual & 51.04 & 5 & 10.21 & & & \\
\hline Lack of Fit & 46.37 & 3 & 15.46 & 6.62 & 0.1340 & not significant \\
\hline Pure Error & 4.67 & 2 & 2.33 & & & \\
\hline Cor Total & 3846.55 & 10 & & & & \\
\hline $\mathbf{R}^{2}$ & 0.9867 & & & & & \\
\hline Adjusted $\mathbf{R}^{2}$ & 0.9760 & & & & & \\
\hline Predicted $\mathbf{R}^{2}$ & 0.9111 & & & & & \\
\hline Adeq Precision & 28.0756 & & & & & \\
\hline
\end{tabular}

Table 6. ANOVA for elongation

\begin{tabular}{lrrrrrr}
\hline \multicolumn{1}{c}{ Source } & \multicolumn{1}{c}{$\begin{array}{c}\text { Sum of } \\
\text { Squares }\end{array}$} & df & $\begin{array}{c}\text { Mean } \\
\text { Square }\end{array}$ & F-value & p-value & \% Contribution \\
\hline Model & 2.35 & 3 & 0.7833 & 27.38 & 0.0007 & significant \\
A-Specimen temp & 1.44 & 1 & 1.44 & 50.50 & 0.0004 & $56.1 \%$ \\
AB & 0.5000 & 1 & 0.5000 & 17.48 & 0.0058 & $19.4 \%$ \\
AC & 0.4050 & 1 & 0.4050 & 14.16 & 0.0094 & $15.7 \%$ \\
Curvature & 0.0547 & 1 & 0.0547 & 1.91 & 0.2160 & \\
Residual & 0.1717 & 6 & 0.0286 & & & \\
Lack of Fit & 0.1650 & 4 & 0.0413 & 12.37 & 0.0762 & not significant \\
Pure Error & 0.0067 & 2 & 0.0033 & & & \\
Cor Total & 2.58 & 10 & & & & \\
R $^{2}$ & 0.9319 & & & & & \\
Adjusted R & 0.8979 & & & & & \\
Predicted R & 0.7323 & 15.7840 & & & &
\end{tabular}




\subsection{Effect of processing parameters on the ultimate tensile strength and elongation}

The influence of the processing parameters on the UTS and elongation of the part is shown in Fig 6. As analyzed in section 3.4, specimen temperature is the parameter that has the greatest influence on these two output factors. The steady rise in specimen temperature reduces the strength and elongation of finished parts because the specimentemperature directly affects the liquid phase fraction of the billets. If the temperature is too low, it is difficult to form. If the temperature is too high, the workpiece is difficult. retains its original shape during formation. The influence of the other two variables is smaller and fairly balanced. Increasing the holding time reduces the strength and elongation while the punch velocity has the opposite effect.

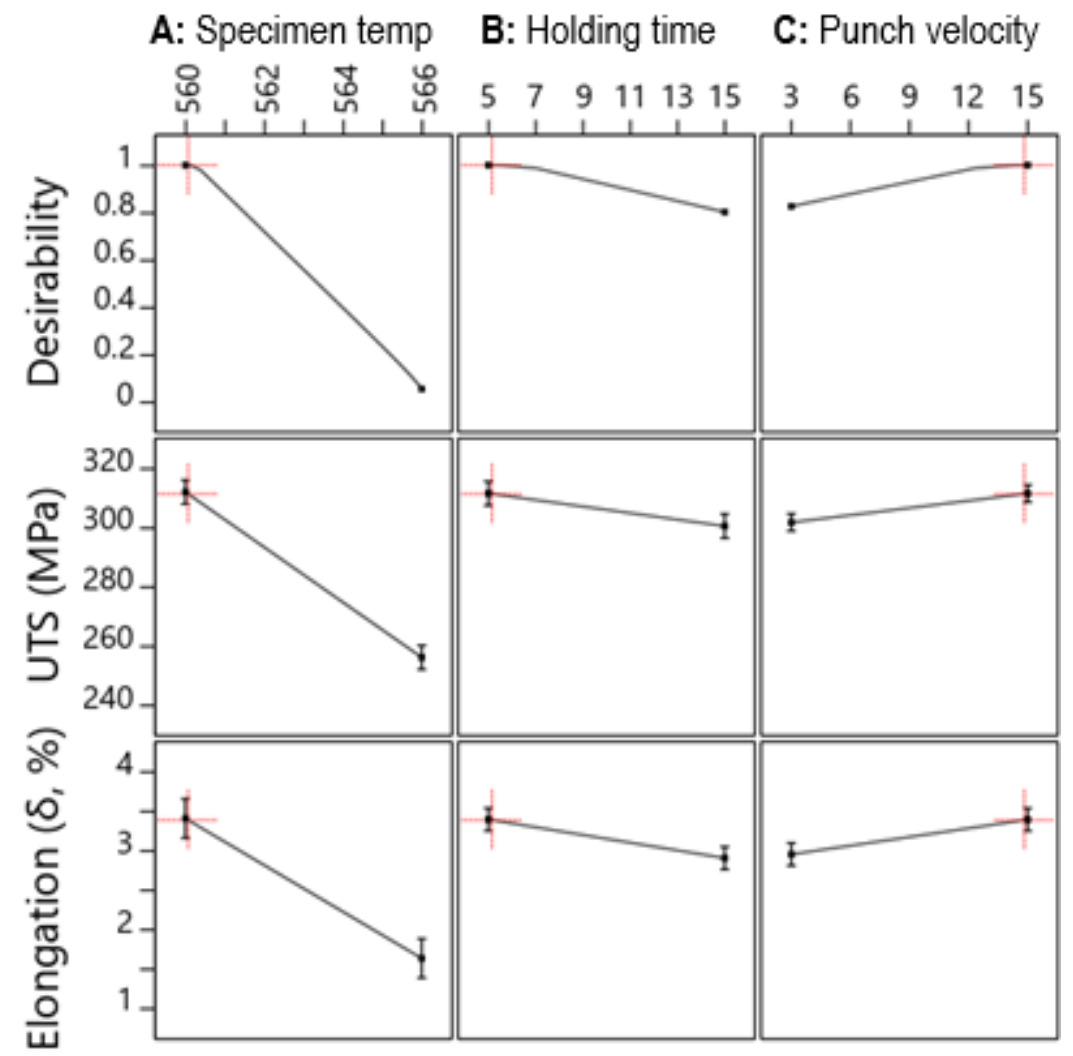

Figure 6. Effect of processing parameters on the ultimate strength and elongation

\section{Optimization of parameters}

Desirability function optimization of regression function has been utilized for all outputs. The optimization process, the main objective was to find out the optimal values of processing condition in order to maximize the value of the UTS and elongation during the thixoextrusion. Optimal values can be selected in Table 7 as follows for specimen temperature $\left(560^{\circ} \mathrm{C}\right)$ holding time $(5 \mathrm{~min})$ and punch speed $(15 \mathrm{~mm} / \mathrm{s})$.

Table 7. Optimization solution

\begin{tabular}{rccccccc}
\hline No. & $\begin{array}{c}\text { Specimen } \\
\text { temp }\end{array}$ & $\begin{array}{c}\text { Holding } \\
\text { time }\end{array}$ & $\begin{array}{c}\text { Punch } \\
\text { velocity }\end{array}$ & UTS & Elongation Desirability & \\
\hline $\mathbf{1}$ & $\mathbf{5 6 0 . 0 6 8}$ & $\mathbf{5 . 1 5 1}$ & $\mathbf{1 4 . 8 3 3}$ & $\mathbf{3 1 1 . 4 3 7}$ & $\mathbf{3 . 3 9 1}$ & $\mathbf{1 . 0 0 0}$ & Selected \\
2 & 560.109 & 5.055 & 14.844 & 311.163 & 3.384 & 1.000 & \\
3 & 560.012 & 5.288 & 14.338 & 311.392 & 3.382 & 1.000 & \\
\hline
\end{tabular}




\section{Conclusions}

This study discusses the application design of experiment to investigate the effects of semi-solid metal process parameters on the UTS and elongation of Aptomat Contact made of ADC12 alloy. The following main conclusions are drawn from this study:

1. Aptomat Contact formed by semi-solid metal process with ADC12 alloy. This is a alloy not recommended for use in this forming method and identified the appropriate forming temperature range for ADC12 alloy is $560-566^{\circ} \mathrm{C}$

2. Creating a uniform globular microstructure in the semi-solid metal process helps improve the mechanical properties of the finished part.

3. The coefficient of determination of the developed regression models for UTS and the elongation are 0.98 and 0.93 , respectively, confirming the effectiveness of the developed regression models.

\section{References}

1. Fan, Z., Semisolid metal processing. International Materials Reviews, 2013. 47(2): p. 49-85 DOI: 10.1179/095066001225001076.

2. Koeune, R. and J.P. Ponthot, A one phase thermomechanical model for the numerical simulation of semi-solid material behavior. Application to thixoforming. International Journal of Plasticity, 2014. 58: p. 120-153 DOI: 10.1016/j.ijplas.2014.01.004.

3. Nafisi, S. and R. Ghomashchi, Semi-solid processing of aluminum alloys. 2016: Springer.

4. Ngo, T.B., A.B. Semenov, and B.I. Semenov, Thixoforming of Wrought Aluminum Alloy 1973. Solid State Phenomena, 2019. 285: p. 203-209 DOI: 10.4028/www.scientific.net/SSP.285.203.

5. Barrirero, J., Eutectic modification of Al-Si casting alloys. 2019: Linköping University Electronic Press.

6. Vinith, S., et al., Fluidity of ADC12 alloy based on theoretical and computational fluid dynamics. 2015. 4: p. 996-999.

7. Wang, S.-z., et al., Formation and Growth Mechanism of Globular Crystal of ADC12 Aluminum Alloy by Near-Liquidus Squeeze Casting. Advances in Mechanical Engineering, 2015. 6 DOI: 10.1155/2014/358754.

8. Wang, Z., et al., Evolution of the semi-solid microstructure of ADC12 alloy in a modified SIMA process. Materials Characterization, 2011. 62(10): p. 925-930 DOI: 10.1016/j.matchar.2011.07.003.

9. Rao, Y., H. Yan, and Z. Hu, Modification of eutectic silicon and $\beta$-Al5FeSi phases in as-cast ADC12 alloys by using samarium addition. Journal of Rare Earths, 2013. 31(9): p. 916-922 DOI: 10.1016/s1002-0721(12)60379-2.

10. Xiong, J., et al., Effects of Yb Addition on the Microstructure and Mechanical Properties of As-Cast ADC12 Alloy. Metals, 2019. 9(1) DOI: $10.3390 /$ met9010108.

11. Liu, D., H.V. Atkinson, and H. Jones, Thermodynamic prediction of thixoformability in alloys based on the Al-Si-Cu and Al-Si-Cu-Mg systems. Acta Materialia, 2005. 53(14): p. 3807-3819 DOI: 10.1016/j.actamat.2005.04.028.

12. Pola, A., M. Tocci, and P. Kapranos, Microstructure and Properties of Semi-Solid Aluminum Alloys: A Literature Review. Metals, 2018. 8(3) DOI: $10.3390 /$ met8030181.

13. JIS H5302 2000 japanese industrial standard. 2000: p. 10.

14. Semenov, A.B., T.B. Ngo, and B.I. Semenov, Thixoforming of Hypereutectic AlSi12Cu2NiMg Automotive Pistons. Solid State Phenomena, 2019. 285: p. 446-452 DOI: 10.4028/www.scientific.net/SSP.285.446.

15. Paskevich, A. and T. Wies, Verified Software. Theories, Tools, and Experiments: 9th International Conference, VSTTE 2017, Heidelberg, Germany, July 22-23, 2017, Revised Selected Papers. Vol. 10712. 2017: Springer. 